\title{
Rostral Elements of Sympatho-motor Circuitry: A Virally Mediated Transsynaptic Tracing Study
}

\author{
Ilan A. Kerman, Huda Akil, and Stanley J. Watson \\ Molecular and Behavioral Neuroscience Institute, University of Michigan, Ann Arbor, Michigan 48105
}

\begin{abstract}
Numerous physiological and emotionally motivated behaviors, including locomotion, exercise, escape, and attack behaviors as well as passive coping responses, require concomitant activation of motor and sympathetic efferents. Such functional heterogeneity suggests the existence of dual function neurons that can simultaneously coordinate motor and sympathetic output. Because previous physiological investigations have implicated a number of mesencephalic and telencephalic regions in mediating these behaviors, we hypothesized the presence of dual function sympatho-motor neurons in these neural structures. To test this hypothesis, we used recombinant strains of the pseudorabies virus (PRV) for transsynaptic tract-tracing. PRV-152, a strain that expresses enhanced green fluorescent protein, was injected into sympathectomized gastrocnemius muscle, whereas PRV-BaBlu, which expresses $\beta$-galactosidase, was injected into the adrenal gland in the same animals. Although coinfected neurons were detected in a number of mesencephalic and telencephalic regions, $>50 \%$ of such neurons were located within specific subdivisions of two general areas: the hypothalamus and periaqueductal gray. These subdivisions included the ventrolateral periaqueductal gray, dorsomedial hypothalamus, dorsolateral lateral hypothalamus, and ventral portion of the medial parvocellular subdivision of the paraventricular nucleus of the hypothalamus (PVN). A subset of the sympathomotor neurons within the PVN also contained either arginine vasopressin or oxytocin. This sympatho-motor circuitry likely plays an important role in mediating different aspects of stress responses and emotionally motivated behaviors.
\end{abstract}

Key words: autonomic; muscle; adrenal; pseudorabies; hypothalamus; periaqueductal gray

\section{Introduction}

Although classical theories regarding autonomic and motor control suggest that these systems are quite disparate (Cannon, 1963), there are numerous examples of behaviors that are characterized by coordinated motor and autonomic regulation, including exercise, startle, defense ("fight-or-flight") reaction, pain responses, reproductive behavior (lordosis), vocalization, righting reflexes, feeding, micturition, and sleep (Hilton, 1982; Eldridge et al., 1985; Lovick, 1991; Daniels et al., 1999; Palmer and Printz, 1999; Kerman et al., 2000a,b). For instance, locomotion and exercise require intermittent and complementary contractions of synergistic muscle groups and simultaneous activation of autonomic and respiratory systems to increase cardiac output and to redistribute blood flow from skin and viscera to contracting muscles (Waldrop et al., 1996). Emotionally motivated behaviors require a similar coordination of motor and autonomic systems; defensive-aggressive behavior, for example, involves somatomotor action [e.g., alerting, hissing, and sudden attack (Mancia and Zanchetti, 1981; Jordan, 1990)] and concomitant

Received Dec. 11, 2005; revised Feb. 10, 2006; accepted Feb. 10, 2006.

This work was supported by the Pritzker Neuropsychiatric Disorders Research Consortium and National Institutes of Health Grant P01 MH042251 (S.J.W.). We thank Dr. Lynn Enquist for his generous gift of viral stocks. We are grateful to Drs. Bill Yates, Irmgard Amrein, and Sarah Clinton for their critical reading of a previous version of this manuscript. We also thank James Beals for his help with preparing illustrations.

Correspondence should be addressed to llan A. Kerman, Molecular and Behavioral Neuroscience Institute, University of Michigan, 205 Zina Pitcher Place, Ann Arbor, MI 48109. E-mail: kerman@umich.edu.

DOI:10.1523/JNEUROSCI.5283-05.2006

Copyright $\odot 2006$ Society for Neuroscience $\quad$ 0270-6474/06/263423-11\$15.00/0 autonomic changes, including increased cardiac output and elevated blood pressure (Hilton, 1982; Jordan, 1990).

Aggressive behavior, or fight-or-flight response to threat, stands in contrast to a more passive coping approach, which may involve an animal "playing dead" (Mancia and Zanchetti, 1981). Passive coping response is often characterized by its own array of behavioral and physiologic changes such as immobilization, subordination, low maternal and sex drives, alterations in blood pressure, and increased corticosteroid secretion (Mancia and Zanchetti, 1981).

Despite compelling behavioral evidence for the possible existence of neural circuits dedicated to sympatho-motor integration, surprisingly little is known regarding their organization. Several studies have examined the role that different brain regions may play in mediating behaviors that require concomitant activation of sympathetic and somatomotor efferent systems. In these studies, one or several brain regions were stimulated either electrically (Abrahams et al., 1960; Yardley and Hilton, 1986) or chemically with injections of excitatory amino acids (Bandler, 1982; Hilton and Redfern, 1986), and then behavioral, somatomotor, and autonomic parameters were simultaneously measured. Electrical stimulation has the potential to activate cell bodies as well as fibers of passage, thus complicating interpretation of observed effects. In contrast, with excitatory amino acid injections, it is not possible to determine whether such stimuli activate neurons with dual motor and autonomic functions or whether they activate separate neuronal populations.

To address this issue of motor and autonomic integration, we 
used viral transsynaptic tracing agents to directly examine the organization of sympatho-motor circuitry. We previously described medullopontine areas that contain sympatho-motor neurons (Kerman et al., 2003). The greatest numbers of such neurons were observed in the ventromedial medulla, suggesting that these cells send direct projections to the spinal cord with putative collaterals to motoneurons and sympathetic preganglionic neurons (Kerman et al., 2003).

We hypothesized the existence of rostrally located dualfunction neurons that have the potential to simultaneously regulate motor and sympathetic functions. We focused our attention on mesencephalic and telencephalic areas that mediate motivated behaviors, which require sympatho-motor integration, and/or contain neurons that send projections to either motor or autonomic targets.

\section{Materials and Methods}

All of the procedures regarding animal use in this study conformed to the National Academy of Sciences Guide for the Care and Use of Laboratory Animals and were approved by the University of Michigan University Committee on Use and Care of Animals.

Overview of experimental procedures. In the present studies, we used transgenic recombinants of an attenuated pseudorabies virus (PRV) strain, PRV-Bartha, for transneuronal tracing of multisynaptic pathways innervating the adrenal gland and gastrocnemius muscle. PRV has preferential tropism for axonal terminals (Vahlne et al., 1978, 1980). It is transported in the retrograde direction from the terminals to the cell body where the viral genome is replicated in the nucleus (Enquist et al., 1998). Capsids are assembled and filled with viral DNA in the nucleus, acquire the mature envelope from a late Golgi compartment, and are transported to sites of afferent synaptic contact where cell-to-cell transneuronal transmission of infection occurs (Card et al., 1993; Enquist et al., 1998). The two viral recombinants that we used were PRV-152 and PRV-BaBlu. Both are derived from PRV-Bartha, which is an attenuated form of the parental strain, PRV-Becker. PRV-BaBlu contains the lac $Z$ gene at the $g G$ locus and produces $\beta$-galactosidase $(\beta$-gal) under the control of the viral $g G$ promoter (Kim et al., 1999). PRV-152 carries the gene coding for enhanced green fluorescent protein (eGFP) at the $g G$ locus, which is constitutively expressed under control of the cytomegalovirus immediate early promoter (Smith et al., 2000). Previous studies have demonstrated that PRV-152 and PRV-BaBlu are transported transsynaptically in a retrograde manner, similarly to PRV-Bartha, and that the two recombinants are capable of simultaneously coinfecting the same neuronal population (Standish et al., 1995; Billig et al., 1999, 2000, 2001; Smith et al., 2000; Kerman et al., 2003).

By injecting PRV-152 into the hindlimb muscle and PRV-BaBlu into the adrenal gland, we demonstrated that the earliest survival time at which double-infected neurons are detected in the medulla is $96 \mathrm{~h}$ after injection (Kerman et al., 2003). Although appreciable numbers of double-infected neurons are observed within the medulla and pons at $120 \mathrm{~h}$ after injection (Kerman et al., 2003). A single replication cycle of the virus is $10-12 \mathrm{~h}$ (Demmin et al., 2001). We therefore decided to extend the survival times by $12 \mathrm{~h}$ to $132-136$ and $144 \mathrm{~h}$. In preliminary experiments, we determined that there is maximal labeling in the forebrain and midbrain at $144 \mathrm{~h}$ of survival, and we thus used that as the longest survival time point. This temporal analysis allowed us to examine the hierarchical organization of the descending sympatho-motor circuits.

Viral recombinants used in the present studies were harvested from pig kidney cell cultures at a titer of $10^{8}$ to $10^{9} \mathrm{pfu} / \mathrm{ml}$. Viral stocks were aliquoted in $50 \mu \mathrm{l}$ volumes and stored at $-80^{\circ} \mathrm{C}$. At the times of injection, viral aliquots were removed from the freezer and kept on ice until immediately before injections.

Male Sprague Dawley rats $(n=14)$ (Charles River Laboratories, Wilmington, MA) were used in these studies. We previously reported a robust negative correlation between the animal's weight and efficiency of infection of gastrocnemius motoneurons, with the largest rate of mo- toneuron infection in rats of intermediate size that weigh $\sim 200 \mathrm{~g}$ (Kerman et al., 2003). Thus, animals in the current study were selected to weigh between 163 and $342 \mathrm{~g}$ for an average of $207 \pm 4.6 \mathrm{~g}$ (mean \pm $\mathrm{SEM}$ ). Animals were anesthetized with $5 \%$ isoflurane vaporized in 1-1.5 $\mathrm{L} / \mathrm{min} \mathrm{O}_{2}$ and maintained with a $1.5-2.5 \%$ concentration. Because of supply problems, in five of the animals, anesthesia was induced and maintained with an intraperitoneal injection of ketamine and xylazine mixture (60 mg/kg ketamine and $7 \mathrm{mg} / \mathrm{kg}$ xylazine). Choice of anesthetic regimen had no effect on viral infection or transport. A surgical plane of anesthesia was achieved under both anesthetic regimens, such that there was no spontaneous movement and there were no withdrawal responses to tail and/or foot pinch. At the conclusion of the survival period following transport of viral tracers, animals were deeply anesthetized intraperitoneally with $1 \mathrm{ml}$ of $50 \mathrm{mg} / \mathrm{ml}$ pentobarbital sodium solution and transcardially perfused with $100-150 \mathrm{ml}$ of physiological saline followed by $400-500 \mathrm{ml}$ of a $4 \%$ paraformaldehyde solution containing $1.4 \% \mathrm{~L}-$ lysine and $0.2 \%$ sodium meta-periodate (PLP) (McLean and Nakane, 1974).

Hindlimb sympathectomy. In addition to motor efferents, the hindlimb is also innervated by sympathetic efferents that project to blood vessels, sweat glands, and other smooth muscle targets (Jänig and McLachlan, 1992). To prevent infection of sympathetic pathways after injection of PRV-152 into the gastrocnemius muscle, the hindlimb was surgically sympathectomized in all animals using a previously described approach (Kerman et al., 2003). Briefly, the lumbar sympathetic nerve was dissected via a ventral laparotomy and was extirpated from the level of the renal artery caudal to the bifurcation of the abdominal aorta. Neural plexuses running along the descending aorta and inferior vena cava were also stripped off under microscopic observation using fine forceps. The abdominal aorta and the inferior vena cava were then swabbed with $10-20 \%$ phenol dissolved in ethylene glycol. Abdominal musculature was closed with sutures, and the overlying skin was closed with surgical staples.

We have found previously that this procedure is effective at removing the large majority of sympathetic efferents to the hindlimb, as evidenced by the lack of infection in the intermediolateral cell column in the same animals that exhibited robust infections of lumbar motoneurons (Kerman et al., 2003). This finding was confirmed in the present study in five animals allowed to survive 120-140 $\mathrm{h}$ after PRV-152 injections into the gastrocnemius muscle. In these animals, the spinal cord was extracted in three blocks: T1-T7 segment, T8-T13, and L1-L6. Thoracic blocks were sectioned in the horizontal plane at 35 or $40 \mu \mathrm{m}$, whereas the lumbar blocks were sectioned either in the horizontal or coronal plane at $40 \mu \mathrm{m}$. A one in three series for each block was processed for simultaneous visualization of PRV-152 and PRV-BaBlu using immunofluorescent methods aimed at the detection of eGFP and $\beta$-gal (see below for methodological details). This analysis confirmed effectiveness of surgical sympathectomy, because there was light infection with PRV-152 in the intermediolateral cell column in only one of the animals. In the same animals, we observed robust infection of gastrocnemius motoneurons with PRV152 , thus further validating this approach for selective infection of motor efferents.

Double-virus injections. To determine the location of neurons coordinating muscle contraction and autonomic activity, rats received injections of PRV-152 into their left $(n=12)$ or right $(n=2)$ gastrocnemius muscle and injections of PRV-BaBlu into their left adrenal gland. The gastrocnemius muscle was injected with a $30 \mu$ total volume of PRV-152, which was divided into multiple injections of $1.0 \mu \mathrm{l}$. The adrenal gland was dissected via a left flank incision and gently separated from surrounding viscera and fat; the adjacent connective tissue was then retracted to facilitate access to the gland. Two or three injections of PRVBaBlu were then made into the gland through a glass pipette attached to a Hamilton syringe; the total volume of virus injected was $2-4 \mu \mathrm{l}$. After each injection, the gland was swabbed with a cotton-tip applicator to decrease nonspecific viral spread. We demonstrated previously that this injection protocol produces an efficient infection of target neurons and does not result in the spread of the virus to nontarget tissues (Kerman et al., 2003).

In two rats, both the gastrocnemius muscle and the adrenal gland were injected with PRV recombinants on the same day; these animals were 
Table 1. Number of times that each rat was allowed to survive after injections of PRV recombinants into the gastrocnemius muscle and adrenal gland

\begin{tabular}{lccr}
\hline Survival period & PRV-152 survival (h) & PRV-BaBlu survival (h) & $n$ \\
\hline Earliest & 96 & 96 & 2 \\
Short & 120 & 96 & 3 \\
& 129 & 107 & 1 \\
Intermediate & 132 & 108 & 3 \\
& 136 & 112 & 1 \\
Late & 144 & 112 & 2 \\
& 144 & 120 & 2 \\
\hline
\end{tabular}

Based on the distribution of their survival times, animals were grouped into four separate survival groups.

allowed to survive $96 \mathrm{~h}$ after the injections. In the other 12 animals, PRV-152 injections into the gastrocnemius muscle preceded PRV-BaBlu injections into the adrenal gland by 22-32 $\mathrm{h}$ to provide for matching of the infection produced by the two recombinants. These animals survived 120-144 h after gastrocnemius muscle injections. Survival times after injections into each target and the numbers of animals in each group are summarized in Table 1.

Tissue processing. After transcardial perfusion with PLP (see above), the entire brain was extracted and postfixed in PLP overnight. Brains were then immersed in $30 \%$ sucrose for $24-48 \mathrm{~h}$ and sectioned coronally at a thickness of 35 or $40 \mu \mathrm{m}$ and collected into six bins. Tissue was stored at $-20^{\circ} \mathrm{C}$ in cryoprotectant $[30 \%$ sucrose, $30 \%$ ethylene glycol, $1 \%$ polyvinyl-pyrrolidine (PVP-40)] until immunohistochemical processing was conducted.

For immunofluorescent detection, tissue was initially rinsed with $0.1 \mathrm{M}$ phosphate buffer $(\mathrm{PB}), \mathrm{pH} 7.4$, several times at room temperature. It was then incubated for $1 \mathrm{~h}$ in a blocking solution made up of $1 \%$ normal donkey serum, $1 \%$ bovine serum albumin, and $0.3 \%$ Triton X-100 in 0.1 м PB. The tissue was then reacted with a mixture of primary antibodies [rabbit anti-GFP IgG (Invitrogen, Eugene, OR) at 1:1000 and mouse anti- $\beta$-gal IgG (Sigma, St. Louis, MO) at 1:1000] diluted in the above blocking solution. After $24-48 \mathrm{~h}$ of incubation at $4^{\circ} \mathrm{C}$ in the primary antibody solution, the tissue was rinsed several times with $0.1 \mathrm{M} \mathrm{PB}$ and then reacted with a secondary antibody solution, which consisted of donkey anti-mouse IgG conjugated to CY3 (1:200; Jackson ImmunoResearch, West Grove, PA) and goat anti-rabbit IgG conjugated to BODIPY FL (1:200; Invitrogen) dissolved in the blocking solution. Thus, PRV152-infected cells appeared green, whereas those infected with PRV$\mathrm{BaBlu}$ were red, and double-infected cells appeared yellow or orange depending on the balance of colors. Specificity of the primary and secondary antibodies used in these double-labeling experiments has been documented previously (Billig et al., 2000; Kerman et al., 2003).

Triple-labeling experiments were also performed for simultaneous detection of the viral reporter proteins and either arginine vasopressin (AVP) or oxytocin (OT). Colocalization studies for AVP and OT were always performed on adjacent sections, so that potential OT content within AVP-containing cells (and vice versa) was not examined. Tissue handling procedures were similar to those described above, and the following primary antibody solution was used: chicken anti-GFP IgY (Abcam, Cambridge, MA) at 1:2000, mouse anti- $\beta$-gal IgG (Sigma) at $1: 1000$, and rabbit anti-AVP at 1:7500 or rabbit anti-OT at 1:10,000. The latter two antibodies were produced in our laboratory and were determined to be specific, because their signal could be eliminated by coincubation with specific peptides. After $36 \mathrm{~h}$ of incubation in the primary antibody solution, the tissue was then incubated for $2 \mathrm{~h}$ in the dark with a secondary antibody mixture containing: donkey anti-mouse IgG conjugated to CY3 (1:200; Jackson ImmunoResearch), goat anti-chicken IgG conjugated to AlexaFluor 488 (1:200; Invitrogen), and biotinylated goat anti-rabbit IgG (Vector Laboratories, Burlingame, CA). After several rinses with $0.1 \mathrm{M} \mathrm{PB}$, the tissue was then incubated with NeutrAvidin conjugated to AlexaFluor 350 (1:200; Invitrogen).

Thus, cells infected with PRV-152 appeared green, those infected with PRV-BaBlu were red, and those expressing AVP or OT were blue. Neurons double-infected with PRV-152 and PRV-BaBlu appeared either yellow or orange, depending on the balance of colors. Double-infected cells that colocalized with either AVP or OT would theoretically be white, because blue, green, and red represent the full spectrum of visible light. However, because of the differences in the balance and intensity of each color, triple-labeled cells were close to white in color with a blue, red, or green tinge to them.

After processing, tissue sections were mounted on glass slides and coverslipped with Aqua Poly/Mount (Polysciences, Warrington, PA).

Tissue analysis. Tissue was examined using a Leica (Nussloch, Germany) DMR photomicroscope. Swanson's (2004) rat atlas and that of Paxinos and Watson (1986) were used as references for anatomical classification. Infected neurons were digitized using a Photometrics (Huntington Beach, CA) CoolSNAP fx $_{\mathrm{x}}$ black and white camera and MCID Elite 7.0 imaging software (Imaging Research, St. Catharines, Ontario, Canada). In $\beta$-gal and eGFP colocalization experiments, double-labeled neurons appeared yellow or orange, depending on color balance, when detected with a dual-band FITC/CY3 filter set (Chroma Technology, Brattleboro, VT) with excitation spectra of 460-500 and 550-575 nm and emission spectra of $510-540$ and $590-680 \mathrm{~nm}$. The presence of each fluorophore within double-labeled neurons was verified using specific filter sets (Chroma Technology) with the following respective excitation and emission ranges: BODIPY FL, 440-520 and 500-555 nm (green fluorescence); CY3, 535-560 and 545-625 nm (red fluorescence). In triple-labeled experiments, cells containing AVP or OT appeared blue when detected with a filter set specific for AlexaFluor 350. Excitation and emission ranges of this filter set were $320-400$ and $410-510 \mathrm{~nm}$, respectively.

Black and white images were obtained using specific filter sets individually. They were then pseudocolored and digitally overlaid using Adobe Photoshop version 8.0 (Adobe Systems, San Jose, CA). GFP-positive neurons were pseudocolored green, $\beta$-gal-containing cells were pseudocolored red, and double-labeled neurons appeared yellow or orange. In the case of triple-labeling experiments AVP- or OT-containing cells were pseudocolored blue. Colocalization of these peptides with viral reporter proteins was determined in images digitized under a $20 \times$ objective and by overlaying pseudocolored images in Adobe Photoshop. Colocalization of two or three fluorophores was determined by turning on and off each layer to determine the location and color of each cell. Brightness and contrast of images were optimized for presentation purposes, and digital images were imported into Canvas 8.0 (Deneba Systems, Miami, FL) or Adobe Photoshop for preparation of figures.

Statistical analysis. Linear regression analyses were performed using Microsoft (Seattle, WA) Excel 2003 for Windows. Multiple means were compared using one-way ANOVA with Tukey's honestly significant difference (HSD) post hoc test for pairwise comparisons (SPSS 13.0 for Windows; SPSS, Chicago, IL); $\chi^{2}$ testing was performed using the $\chi^{2}$ Calculator (http://www.georgetown.edu/faculty/ballc/webtools/ web_chi.html). The significance level was set as $p<0.05$.

\section{Results}

Animals used in this study $(n=14)$ were arranged into four groups based on their survival times (Table 1): earliest survival group ( $n=2)$, short survival group $(n=4)$, intermediate survival group $(n=4)$, and late survival group $(n=4)$. Initial analysis focused on qualitative characterization of areas that contained double-labeled neurons, which were coinfected with PRV-152 and PRV-BaBlu. All of the regions examined contained singleand double-labeled cells. With exception of the cerebellum, which contained only cells infected with PRV-152 at the later survival times, no brain regions were observed that contained only cells infected with one PRV recombinant but not the other.

\section{Early survival times}

At the earliest survival time, $96 \mathrm{~h}$ for both PRV strains, there were low to moderate numbers of double-infected cells in medullopontine sites as reported previously (Kerman et al., 2003). There were also low to moderate numbers of double-infected neurons in the periaqueductal gray (PAG), lateral hypothalamus $(\mathrm{LH})$, and paraventricular nucleus of the hypothalamus (PVN). 
Occasional double-infected neurons were also present in the posterior hypothalamus $(\mathrm{PH})$, dorsomedial hypothalamus (DMH), and Edinger-Westphal nucleus (EW). Neurons infected either with PRV-152 or PRV-BaBlu, but not infected with both viral strains, were also present in the red nucleus (RN).

To better match the temporal progression of infection, viral injections were separated in time in subsequent experiments. Accordingly, injections of PRV-152 into the gastrocnemius muscle preceded those of PRV-BaBlu into the adrenal gland by $22-32 \mathrm{~h}$ (Table 1). Survival times were also increased to determine the temporal pattern of infection and the maximal amount of labeling in each region.

In the short survival group (where PRV-152 and PRV-BaBlu injections were staggered by $22-32 \mathrm{~h}$ ), there were moderate numbers of double-infected cells in the PAG. There was also a moderate number of double-infected cells in the EW in two of the four animals. In the other two animals, there was a moderate infection with PRV-BaBlu in that region but no PRV-152-infected neurons. There were low to moderate numbers of double-infected cells in the RN. In the hypothalamus, there were low numbers of double-infected neurons in the $\mathrm{PH}$, with low to moderate labeling in the DMH, LH, and PVN.

\section{Intermediate survival time}

In the intermediate survival group, there were moderate to large numbers of double-infected neurons in the PAG (Fig. 1). There were also moderate numbers of double-infected neurons in the $\mathrm{RN}$ and EW in three of the rats, with scattered double-infected neurons present in these areas in the remaining animal (Fig. 1). In the hypothalamus, there were low numbers of double-infected neurons in the $\mathrm{PH}$ with moderate numbers of double-infected neurons in the LH, DMH, and PVN (Figs. 2, 3).

\section{Late survival time}

In the late survival group, there was moderate to heavy labeling with double-infected neurons in the PAG (Fig. 1). There were low to moderate numbers of double-infected neurons in the RN (Fig. $1)$, whereas in the EW, there were moderate numbers of doublelabeled neurons (Fig. 1). In the $\mathrm{PH}$, there were moderate numbers of double-infected neurons. In the $\mathrm{DMH}$, there were moderate to heavy numbers of double-labeled neurons (Fig. 2). In the $\mathrm{LH}$, there was moderate to heavy labeling in two of the rats (Fig. 2 ), whereas the PVN contained moderate numbers of doubleinfected neurons (Fig. 3).

In addition to the mesencephalic and hypothalamic areas described above, double-labeled neurons were also found within the deep layers of the motor cortex (Fig. 4). These neurons were observed in five animals, three of them were in the late survival group, with one in the intermediate survival group and one in the early survival group. In four of these animals, scattered doublelabeled neurons were observed, and in one of the late-surviving animals, low numbers were present.

To quantify the temporal progression of viral infection, the numbers of double-infected neurons in different brain regions were scored on a six point scale from 0 to 5 , where 0 represents no double-labeled neurons, 1 represents scattered neurons, 2 represents light labeling, 3 represents moderate numbers of doublelabeled neurons, 4 represents heavy labeling, and 5 represents very heavy labeling. Each area was scored in each rat and then was averaged across all animals (Table 2). This analysis revealed that at the earliest survival time, there were scattered double-labeled neurons in the LH and PVN, and scattered to light labeling in the PAG. At short survival times, labeling in these areas became
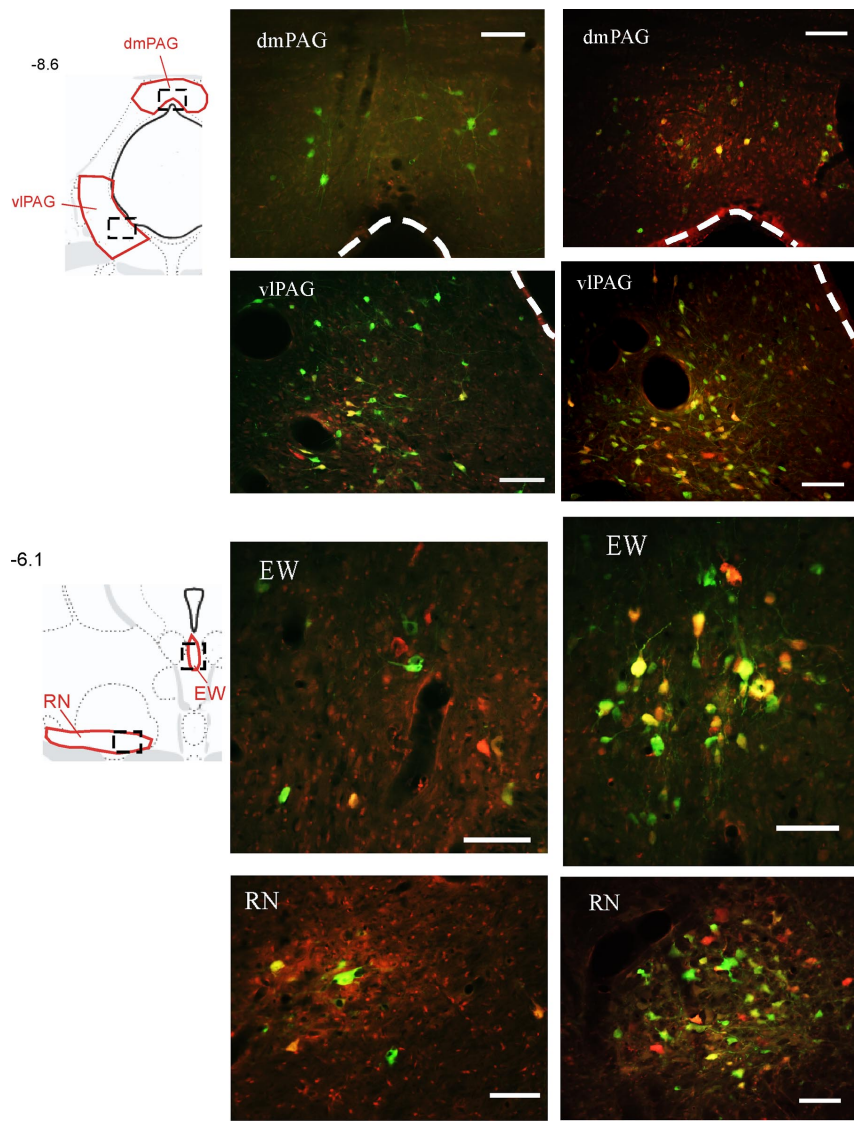

Figure 1. Examples of sympatho-motor neurons in the midbrain. Transsynaptically labeled neurons infected with PRV-152, which was injected into the gastrocnemius muscle, appear green, whereas those infected with PRV-BaBlu were pseudocolored with red; double-infected neurons appear yellow or orange. Drawings in the left column are from Swanson's rat atlas (Swanson, 2004) and indicate locations of anatomical regions shown to the right. Areas shown in red indicate boundaries that were used for cell quantifications, whereas boxes drawn with dashed lines indicate approximate locations of images on the right. Images in the middle column were taken from an animal that survived 132 and $108 \mathrm{~h}$ after injections with PRV-152 and PRV-BaBlu, respectively. Images in the right column are from an animal that survived 144 and $120 \mathrm{~h}$ after injections with PRV-152 and PRV-BaBlu, respectively. Numbers on the left indicate approximate distances from bregma in millimeters. dmPAG, Dorsomedial periaqueductal gray. Scale bars, $100 \mu \mathrm{m}$.

heavier, whereas appreciable signal also appeared in the $\mathrm{DMH}$, EW, and RN. Interestingly, signal in the PAG, PVN, and EW reached its maximum at the short and intermediate survival period. The signal in $\mathrm{RN}$ reached its peak at the intermediate survival point, whereas labeling in the $\mathrm{LH}, \mathrm{PH}$, and $\mathrm{DMH}$ reached its peak at the late survival period (Table 2).

\section{Cell counts}

To determine the relative contribution of the midbrain and hypothalamic areas to sympatho-motor control, detailed cell counts were performed in each of these regions. Motor cortex was excluded from this analysis because of only sparse labeling in some of the animals in this region. The PAG, PH, LH, and PVN were divided into subregions based on functional and connectional grounds. Because PAG is made up of functionally distinct columns running along the rostrocaudal extent of the nucleus (Bandler et al., 1991; Beitz, 1995), it was divided into ventrolateral, dorsolateral, and dorsomedial compartments (Swanson, 2004). To examine possible rostrocaudal differences in the distribution of sympatho-motor neurons, these columns were exam- 

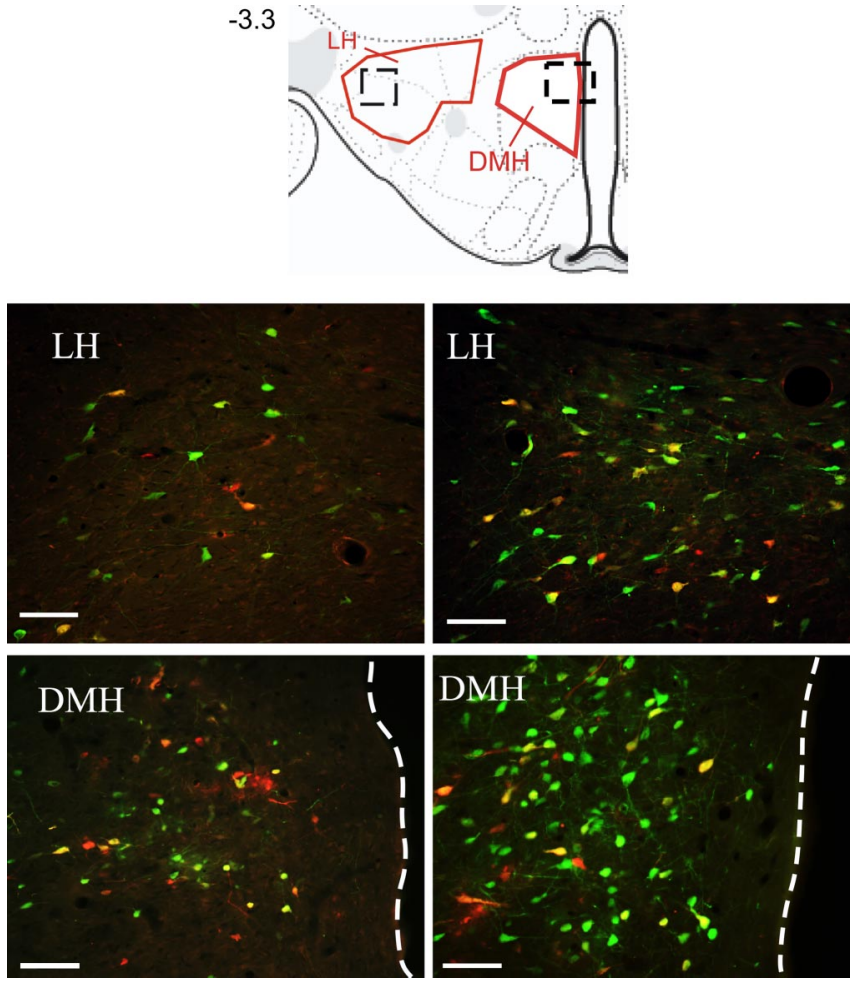

Figure 2. Examples of sympatho-motor neurons in the hypothalamus. The drawing at the top is from Swanson's (2004) rat atlas and indicates locations of anatomical regions shown below. Areas shown in red indicate boundaries that were used for cell quantifications, whereas boxes drawn with dashed lines indicate approximate locations of images below. The number on the left indicates approximate distance from bregma in millimeters. Images in the left column were taken from animals that survived 132 and $108 \mathrm{~h}$ after injections with PRV-152 and PRVBaBlu, respectively. Images in the right column are from animals that survived 144 and $120 \mathrm{~h}$ after injections with PRV-152 and PRV-BaBlu, respectively. Dashed lines show the border of the third ventricle. Scale bars, $100 \mu \mathrm{m}$.

ined at four different rostrocaudal levels, which were approximately $-8.6 \mathrm{~mm}$ from bregma (caudal PAG), $-7.9 \mathrm{~mm}$ from bregma (intermediate PAG), $-6.0 \mathrm{~mm}$ from bregma (intermediate rostral PAG), and $-5.3 \mathrm{~mm}$ from bregma (rostral PAG). Similarly, neurons of the posterior hypothalamus have been reported to differ along its rostrocaudal extent in their neurochemical content and their afferent input (Abrahamson and Moore, 2001). Therefore, this nucleus was sampled at two distinct rostrocaudal levels: posterior at approximately $-4.5 \mathrm{~mm}$ from bregma and rostral at $-4.1 \mathrm{~mm}$ from bregma. Likewise, based on connectional and functional grounds, the LH can be separated into two distinct regions: the perifornical region, which produces pressor responses when chemically stimulated (Allen and Cechetto, 1992), and the lateral region, which produces depressor responses when stimulated (Allen and Cechetto, 1992). Finally, the PVN is made up of functionally and neurochemically distinct subnuclei, which include lateral parvocellular subdivision (PVNlp), posterior magnocellular (PVNpm), and medial parvocellular dorsal and medial parvocellular ventral subdivisions (Swanson, 1987). Each of these regions was analyzed separately. In addition, the $\mathrm{DMH}, \mathrm{EW}$, and $\mathrm{RN}$ were also included in the analysis.

Cell counting was performed in animals in the short, intermediate, and late survival groups. For each area, numbers of doublelabeled cells were determined from one or two sections and were expressed as number of cells/section. Numbers of double-labeled cells across multiple regions were then added together. Survival
A
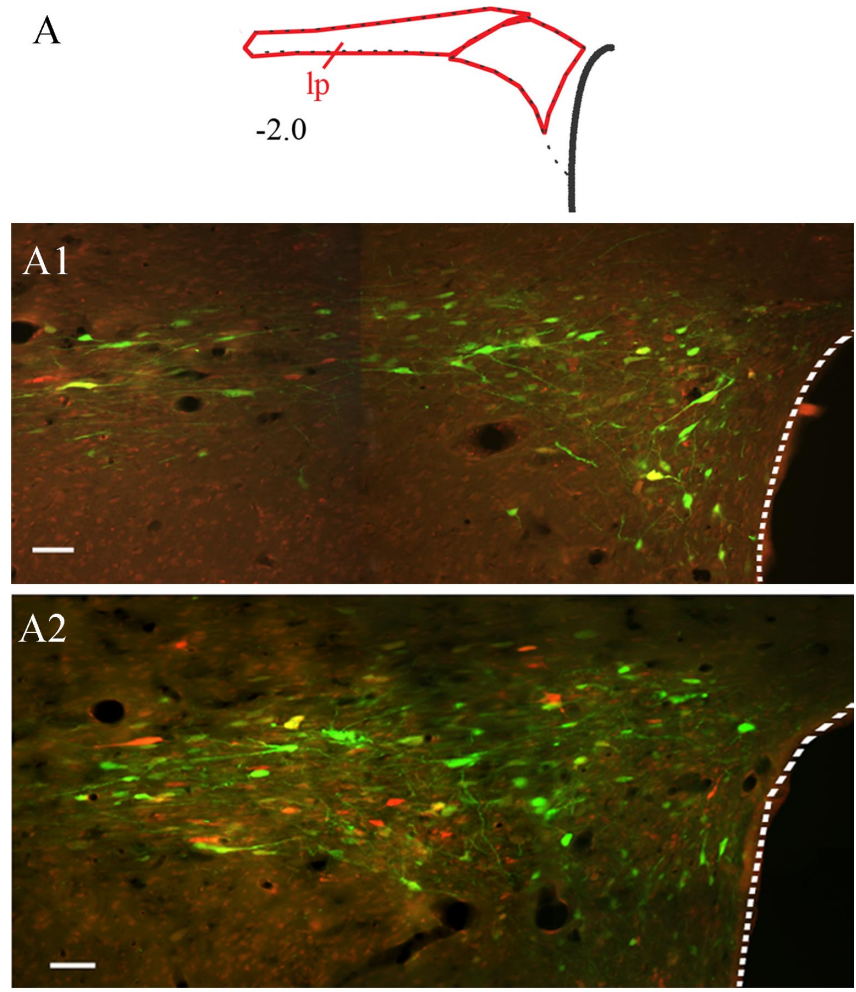

B
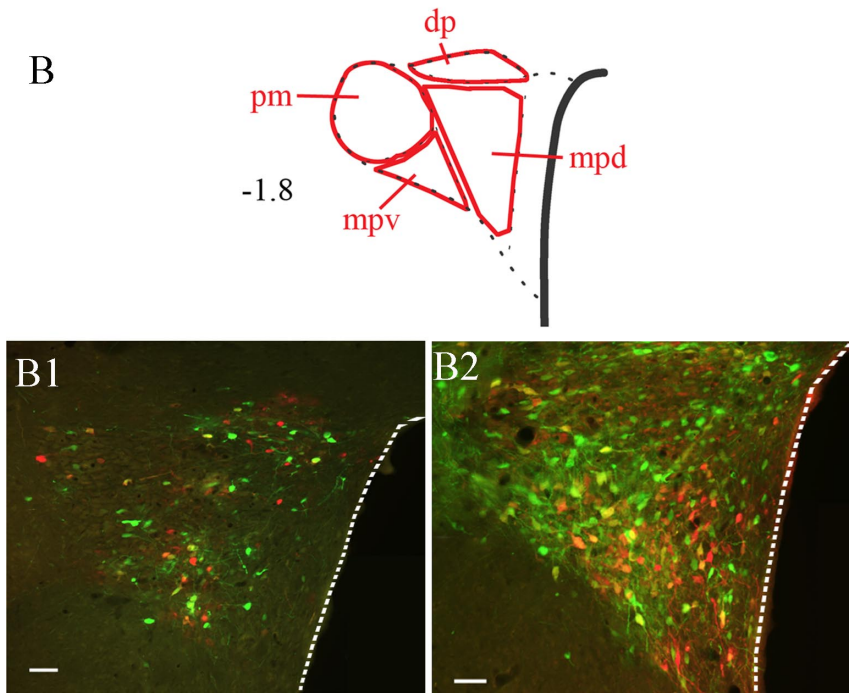

Figure 3. Sympatho-motor neurons in the paraventricular nucleus of the hypothalamus. Images illustrate labeling at two different levels of the nucleus: $\boldsymbol{A}$, caudal; $\boldsymbol{B}$, rostral. Drawings at the top of each panel indicate different subdivisions of the nucleus; numbers to the left of the drawings indicate approximate distances from bregma in millimeters. Images $\boldsymbol{A} \mathbf{1}$ and $\boldsymbol{B} \mathbf{1}$ were taken from an animal that survived 132 and $108 \mathrm{~h}$ after injections with PRV-152 and PRV-BaBlu, respectively. Images in $\boldsymbol{A} \mathbf{2}$ and $\mathbf{B} \mathbf{2}$ are from animals that survived 144 and $120 \mathrm{~h}$ after injections with PRV-152 and PRV-BaBlu, respectively. Note the distinct pattern of labeling as the majority of double-infected cells are found within the lateral parvocellular, dorsal parvocellular, and medial parvocellular ventral subdivisions. Dashed lines outline the edge of the third ventricle. $\mathrm{dp}$, Dorsal parvocellular; Ip, lateral parvocellular; mpd, medial parvocellular dorsal division; $\mathrm{mpv}$, medial parvocellular ventral division; pm, posterior magnocellular. Scale bars, $50 \mu \mathrm{m}$.

time had a significant effect on the number of observed doubleinfected neurons, both as a function of the survival time after PRV-152 as well as the PRV-BaBlu injections (Fig. 5).

To determine the relative contribution of each region to sympatho-motor control, cell counts from each area were divided by the total number of double-infected cells detected in 
each animal. Comparison of the fractions of double-labeled neurons revealed a distinct pattern of labeling within the different regions. Within the PAG, the greatest numbers of double-labeled cells were found within the caudal ventrolateral portions of the nucleus (see Fig. 1), with very few double-infected cells within the rostral dorsolateral portions of the nucleus. Furthermore, at more rostral levels, labeling in the ventrolateral column of the PAG decreased to the levels observed in the rostral dorsomedial region of this nucleus. Within the lateral hypothalamic area, there was a dense cluster of double-labeled cells near the fornix in the perifornical area. However, a majority of doublelabeled cells in this region were located dorsally and laterally to the fornix (Fig. 2). Likewise, there was a distinct pattern of labeling in the PVN, with the majority of double-labeled cells located in the PVNlp, PVNdp, and PVNmpv (Fig. 3).

To determine whether these differences were statistically significant, values from all of the regions were analyzed together using a one-way ANOVA and Tukey's HSD post hoc tests for pairwise comparisons. This analysis revealed that of the 24 areas examined, approximately half of all of the double-labeled neurons detected in each animal were located within five main regions: caudal ventrolateral PAG (cVLPAG), intermediate ventrolateral PAG (iVLPAG), DMH, dorsolateral LH (dlLH), and PVNmpv (Fig. 6). Content of doubleinfected neurons within the cVLPAG, iVLPAG, and dlLH was significantly greater than that within any of the other regions $(p<0.05)$ (Fig. 6). Similarly, content of double-labeled neurons in the DMH and PVNmpv was greater than that of 15 other regions $(p<0.05)$.

\section{Colocalization studies}

Because the PVN contained proportion-

ally more neurons infected with both PRV strains than most of the other regions examined, and it appeared to contain the densest concentration of such neurons, we focused our additional analysis on this nucleus. Specifically, we attempted to determine whether sympatho-motor cells in this nucleus exhibit any relationship to the distribution of AVP- and OT-containing neurons. To address this issue, we processed adjacent tissue bins from five animals for simultaneous visualization of $\beta$-gal, eGFP, and AVP or for $\beta$-gal, eGFP, and OT. In these experiments, AVP- and OT-containing neurons were tagged with a blue fluorophore, whereas the viral reporter proteins were detected as before. One of the animals used in these studies was in the short survival group, two were in the intermediate survival group, and two remaining animals were in the late survival group. AVP- and OT-containing neurons were distributed throughout the PVN. There was a cluster of these cells within the posterior magnocellular subdivision of the PVN; however, this clustering was heavier
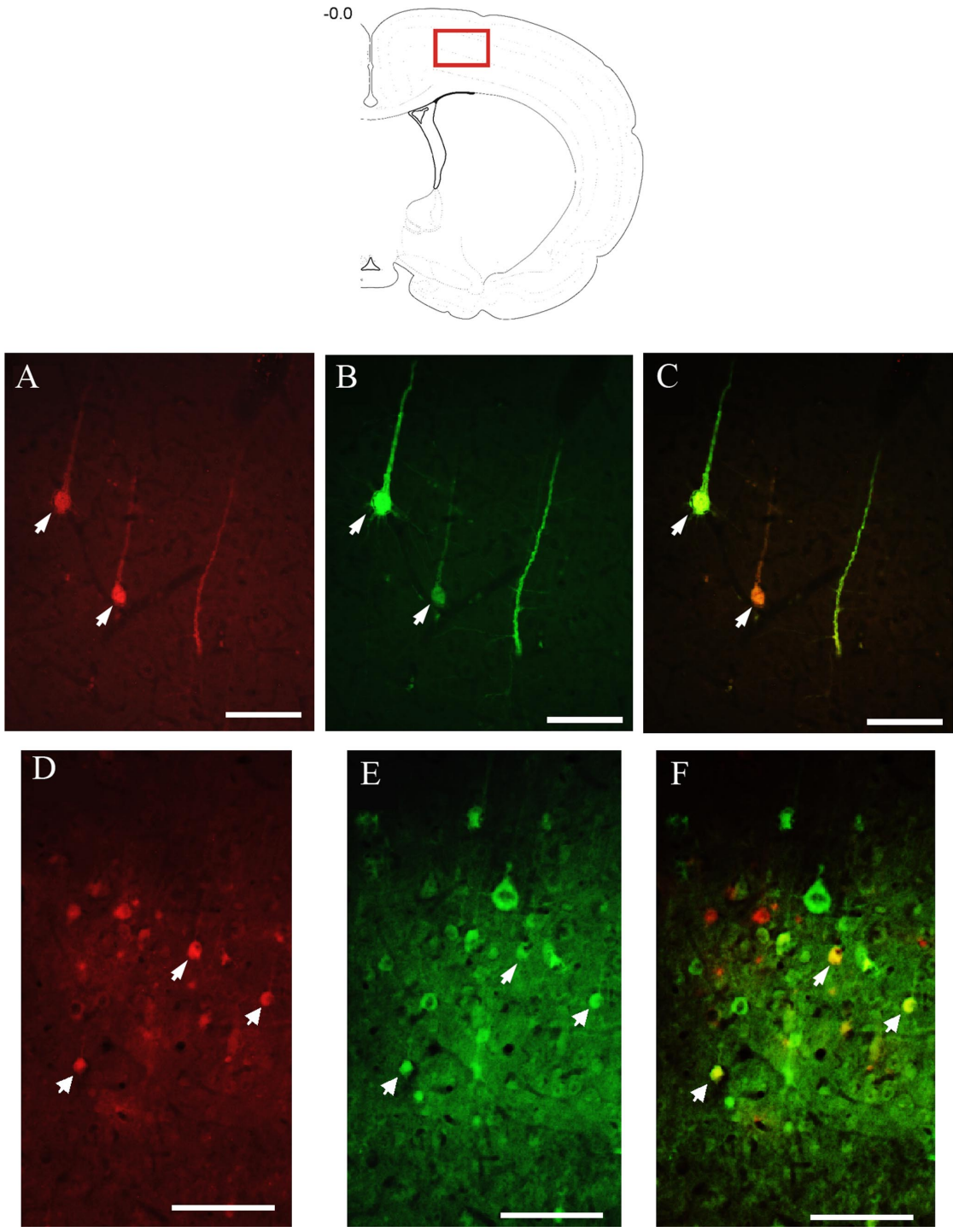

Figure 4. Sympatho-motor neurons in the motor cortex. The red box in the top drawing indicates the approximate location from which the images were digitized. Images $\boldsymbol{A}-\boldsymbol{C}$ were taken from an animal that survived 120 and $96 \mathrm{~h}$ after injections of PRV-152 and PRV-BaBlu, respectively. Images $\boldsymbol{D}-\boldsymbol{F}$ are from animals that survived 144 and $120 \mathrm{~h}$ after injections of PRV-152 and gland; $\boldsymbol{B}$ and $\boldsymbol{E}$ show neurons infected with PRV-152, which send transsynaptic projections to the gastrocnemius muscle; $\boldsymbol{C}$ and $\boldsymbol{F}$ show overlaid images of $\boldsymbol{A}$ plus $\boldsymbol{B}$ and $\boldsymbol{D}$ plus $\boldsymbol{E}$, respectively. Arrows indicate double-labeled neurons. Scale bars, $100 \mu \mathrm{m}$.

Table 2. Relative content of double-infected neurons in different brain regions

\begin{tabular}{llrcc}
\hline & Earliest & \multicolumn{1}{c}{ Short } & Intermediate & \multicolumn{1}{l}{ Late } \\
\hline PAG & 1.5 & $2.4 \pm 0.4$ & $3.25 \pm 0.3$ & $3.25 \pm 0.9$ \\
LH & 1 & $1.75 \pm 0.5$ & $2.75 \pm 0.3$ & $3.75 \pm 0.5^{a, b}$ \\
PVN & 1 & $2.2 \pm 0.4$ & $2.5 \pm 0.3$ & $2.5 \pm 0.3$ \\
RN & 0 & $1.2 \pm 0.4$ & $2.5 \pm 0.5^{a}$ & $2.25 \pm 0.3^{a}$ \\
EW & 0.5 & $1.6 \pm 0.6$ & $2.5 \pm 0.5$ & $2.75 \pm 0.5$ \\
PH & 0.5 & $0.75 \pm 0.5$ & $1.5 \pm 0.3$ & $3.25 \pm 0.6^{a, b}$ \\
DMH & 0.5 & $1.75 \pm 0.5$ & $2.25 \pm 0.3$ & $3.5 \pm 0.3^{a, b}$ \\
\hline
\end{tabular}

Degree of labeling was scored on a scale in which $0=$ no neurons, $1=$ scattered neurons, $2=$ light label, $3=$ moderate label, $4=$ heavy label, and $5=$ very heavy label. Values represent mean \pm SEM.

${ }^{a} p<0.05$ compared with the earliest survival time (ANOVA with Tukey's HSD post hoc test).

${ }^{b} p<0.05$ compared with short survival time (ANOVA with Tukey's HSD post hoc test).

for AVP-containing neurons (Fig. 7). There was also considerable interdigitation of AVP- or OT-containing neurons with those infected with one or both of the PRV strains. These overlapping 


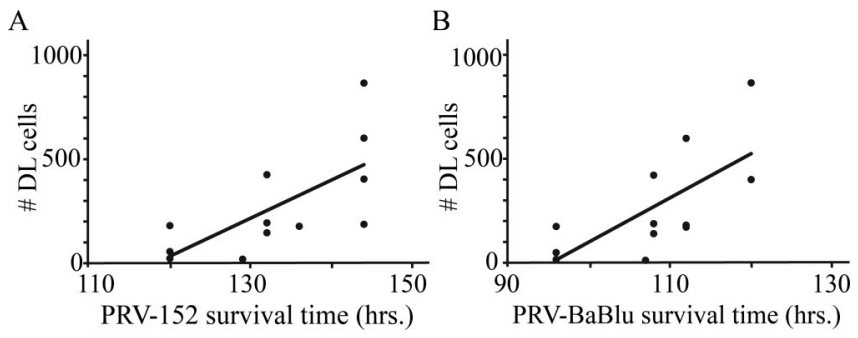

Figure 5. Effect of increasing survival times on the number of double-infected neurons. There was a significant correlation between the length of the postinjection survival period for both PRV-152 $\left(r^{2}=0.48 ; p<0.05 ; \boldsymbol{A}\right)$ and PRV-BaBlu $\left(r^{2}=0.48 ; p<0.05 ; \boldsymbol{B}\right)$. DL, Double labeled.

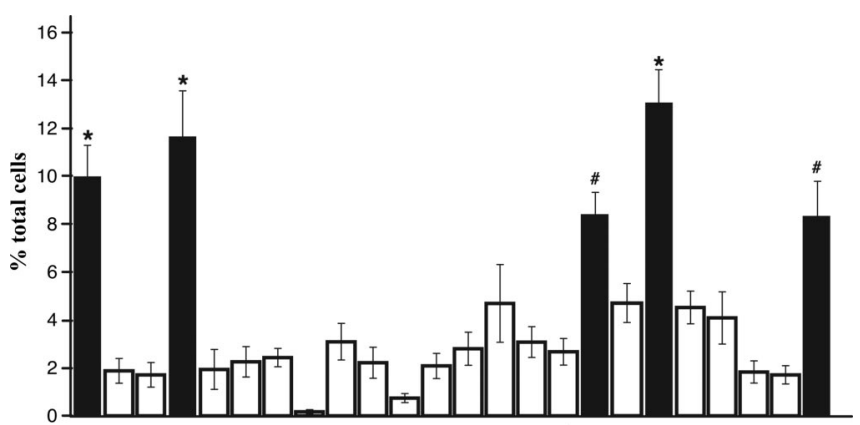

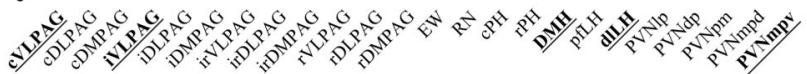

Figure 6. Distribution of sympatho-motor neurons among different regions of the midbrain and hypothalamus. Black bars indicate areas that contained $>50 \%$ of all of the double-infected cells that were detected in each animal. ${ }^{*} p<0.05$, significantly $>19$ other regions; ${ }^{\sharp} p<0.05$, significantly $>15$ other regions. CDLPAG, Caudal dorsolateral periaqueductal gray; CDMPAG, caudal dorsomedial periaqueductal gray; CPH, caudal posterior hypothalamus; iDLPAG, intermediate dorsolateral periaqueductal gray; iDMPAG, intermediate dorsomedial periaqueductal gray; irDLPAG, intermediate rostral dorsolateral periaqueductal gray; irDMPAG, intermediate rostral dorsomedial periaqueductal gray; irVLPAG, intermediate rostral ventrolateral periaqueductal gray; rDLPAG, rostral dorsolateral periaqueductal gray; rDMPAG, rostral dorsomedial periaqueductal gray; pfLH, perifornical lateral hypothalamus; PVNdp, paraventricular nucleus, dorsal parvocellular subdivision; PVNmpd, paraventricular nucleus, medial parvocellular dorsal subdivision; rPH, rostral posterior hypothalamus; rVLPAG, rostral ventrolateral periaqueductal gray.

populations included cells within the parvocellular and magnocellular subdivisions (Fig. 7).

A number of neurons were detected within these regions that were infected with PRV-152 and/or PRV-BaBlu and that also contained either AVP or OT (Fig. 8). For the AVP colocalization study, a total of 348 double-infected neurons (cells that colocalized $\beta$-gal and eGFP) were detected, with 37 (or 11\%) of those cells also AVP positive. Triple-labeled neurons were detected in all subdivisions of the PVN; however, almost half of these cells (18 of $37 ; 49 \%$ ) were concentrated in the posterior magnocellular subdivision (Fig. 9A). These cells were primarily confined to the edge of PVNpm and may represent laterally displaced parvocellular neurons. A similar pattern was observed for neurons that colocalized one of the PRV strains and AVP. Accordingly, 21 of $36(58 \%)$ neurons positive for both $\beta$-gal and AVP were detected with PVNpm, whereas 30 of $48(63 \%)$ eGFP- and AVP-positive neurons were located in the PVNpm.

For the OT colocalization study, a total of 324 double-infected neurons (cells that colocalized $\beta$-gal and eGFP) were detected, with 42 (or 13\%) of those cells also OT positive. In contrast to AVP, only $10 \%$ (or 4 of 42 ) of these cells were found within the posterior magnocellular subdivision (Fig. 9B). This difference
A
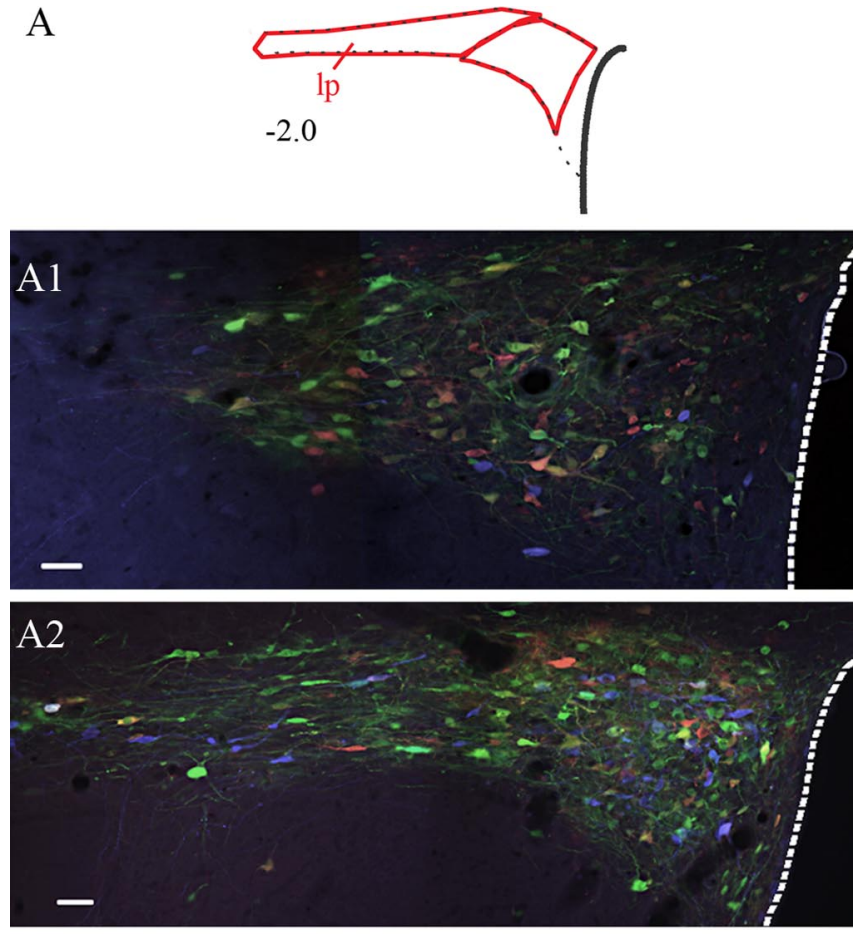

B
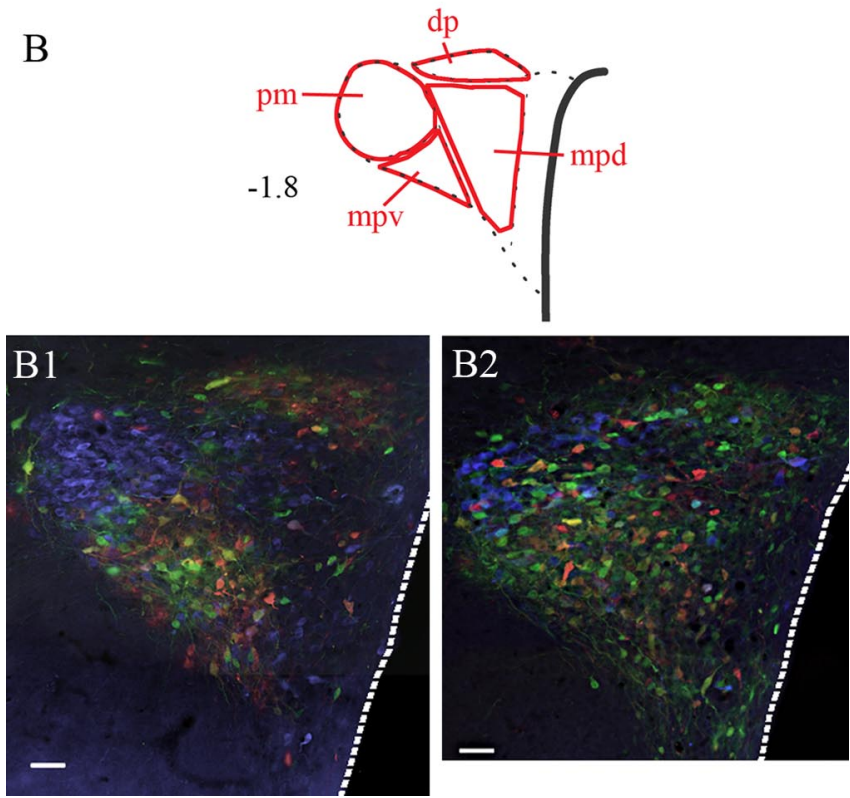

Figure 7. Relationship of sympatho-motor neurons to AVP- and OT-containing neurons in the PVN. Sections were processed for simultaneous visualization of viral reporter proteins ( $\beta$ gal and eGFP) as well as AVP $(\boldsymbol{A} 1, \boldsymbol{B} 1)$ or OT $(\boldsymbol{A 2}, \boldsymbol{B} \mathbf{2})$. $\beta$-Gal and eGFP were tagged with red and green fluorophores, whereas AVP and OT were tagged with a blue fluorophore. Note the extensive interdigitation of AVP-positive $(\boldsymbol{A 1}, \boldsymbol{B} 1)$ and 0T-positive $(\boldsymbol{A 2}, \boldsymbol{B 2})$ neurons with virally infected cells. Also note the differences in the distribution of AVP and OT within the PVN. Although AVP-positive neurons are found within all of the different subdivisions of the PVN, these cells are enriched in the posterior magnocellular (pm) subdivision (B1). In contrast, 0Tcontaining cells show only light clustering within the pm subdivision but instead are scattered throughout the PVN $(\boldsymbol{A 2}, \mathbf{B 2})$. Abbreviations are as in Figure 3. Scale bars, $50 \mu \mathrm{m}$.

was statistically significant $\left(p<0.01 ; \chi^{2}\right.$ test), indicating that a greater fraction of AVP-positive sympatho-motor neurons was found within PVNpm compared with OT-containing neurons. Instead, a majority of OT-containing sympatho-motor neurons (33 of 42;79\%) were found within the PVNlp, PVNdp, and PVNmpv (Fig. 9B). When compared with the distribution of 
OT-containing sympatho-motor neurons, this difference was also significantly different $\left(p<0.01 ; \chi^{2}\right.$ test), indicating that a greater fraction of OT-positive sympathomotor neurons was found within PVNlp, PVNdp, and PVNmpv compared with AVP-containing neurons.

\section{Discussion}

The current study exploited the functions of PRV recombinants as transsynaptic tract-tracing agents that are capable of coinfecting the same neuron. Our observations suggest that several areas may participate in sympatho-motor integration. However, the greatest numbers of rostral sympatho-motor neurons are concentrated in specific subdivisions of two primary structures: the periaqueductal gray and the hypothalamus. These subdivisions include caudal and intermediate VLPAG, dlLH, DMH, and PVNmpv. The PVN also appeared to contain the greatest density of sympatho-motor neurons, some of which also expressed either AVP or OT within its distinct subdivisions.

\section{Methodological considerations}

One limitation of the viral transsynaptic tracing method is that infection with one PRV strain makes the host cell less susceptible to infection with another PRV strain (Kim et al., 1999). Furthermore, viral infection interferes with normal metabolism of the host cell and decreases its normal transcriptional and translational activities (Kim et al., 1999; Card, 2001). Therefore, it is likely that our counts of coinfected cells underestimate actual numbers of sympatho-motor neurons. Likewise, our counts of double-infected neurons that colocalize with either AVP or OT may also underestimate the true overlap of these populations.

When interpreting these data, it is important to keep in mind that PRV is transported transsynaptically. Therefore, we cannot be entirely sure whether our data represent neurons with direct or polysynaptic projections. Furthermore, viral transport may be affected by the distance from the injection site, terminal density at the injection site, and the speed of replication in the injected tissue and in the infected neurons in the pathway (Card, 2001; Cano et al., 2004).

\section{Connectional considerations}

One way to address methodological constraints discussed above is to examine the patterns of labeling at different postinoculation times. Our data revealed that the LH, PVN, and PAG contain double-infected neurons at the earliest survival time when double-infected neurons are observed in the brain. This finding suggests that neurons within these regions send direct collateralized projections to sympathetic preganglionic neurons and to motoneurons. This notion is consistent with monosynaptic tracing studies that demonstrated direct spinal projections from these areas (Saper et al., 1976, 1979; Hosoya, 1980; Swanson and Kuypers, 1980; Haring and Davis, 1983; Kohler et al., 1984; Shiosaka et al., 1985; Mouton and Holstege, 1994; Marson and Foley, 2004). Additionally, the LH contains neurons with descending projections to the ventromedial medulla (Hosoya,
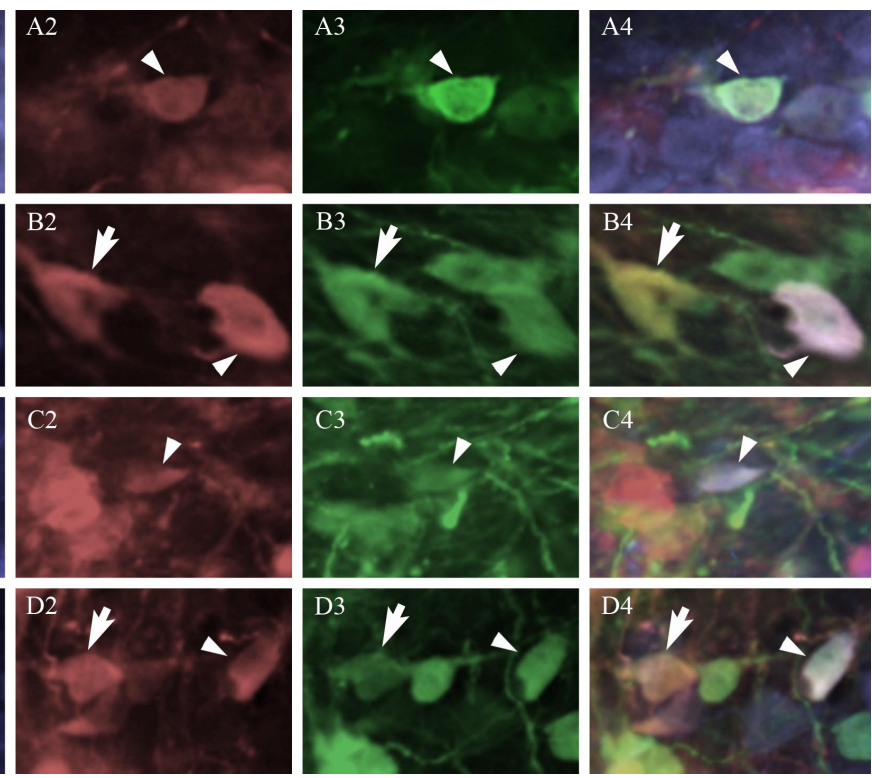

Figure 8. Neurons expressing viral reporter proteins are colocalized with $\operatorname{AVP}(\boldsymbol{A}, \boldsymbol{B})$ or OT $(\boldsymbol{C}, \boldsymbol{D})$ within the PVN. AVP- and OT-expressing neurons were tagged with a blue fluorophore $(A 1, B 1, C 1, D 1)$, those infected with PRV-BaBlu were tagged with a

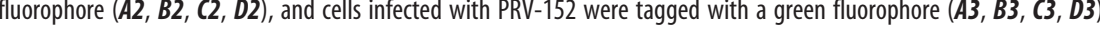
lular ventral (D) subdivisions on the PVN. Arrows show examples of neurons coinfected with both viral strains but not colocalized with either peptide. Scale bar, $20 \mu \mathrm{m}$.

A

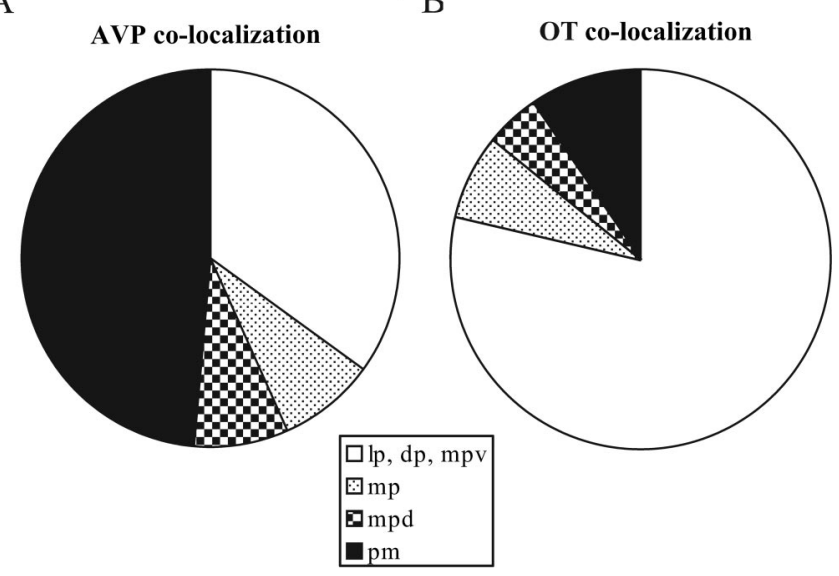

Figure 9. Regional differences in colocalization of AVP with sympatho-motor neurons and that of OT with sympatho-motor neurons. In the case of AVP, nearly one-half (49\%) of the cells that colocalized with AVP and both viral reporter proteins were found within the posterior magnocellular (pm) subdivision $(\boldsymbol{A})$. In contrast, only a small proportion (10\%) of sympathomotor neurons that colocalized with OT was located within the pm subdivision $(\boldsymbol{B})$. Instead, such neurons were found predominantly (79\%) within the lateral parvocellular (Ip), dorsal parvocellular (dp), and medial parvocellular ventral (mpv) subdivisions $(\boldsymbol{B})$. These regions of the PVN also contained a considerable fraction (35\%) of AVP-positive sympatho-motor neurons (A).

1985); therefore, viral transport via this pathway may account for the significant increase in LH labeling at the late survival point.

In contrast, double-infected neurons within the $\mathrm{DMH}, \mathrm{EW}$, $\mathrm{PH}$, and $\mathrm{RN}$ may represent second-order projection neurons, because labeling within these regions did not reach appreciable levels until the short survival time. In the case of $\mathrm{DMH}$, the most likely route of its infection is via its efferent connections with PVN (Hosoya, 1985; ter Horst and Luiten, 1986; Thompson et al., 1996; Hermann et al., 1997). Increasing survival time signifi- 
cantly increased the numbers of double-labeled neurons within the $\mathrm{DMH}$, suggesting an additional source of viral transport to this nucleus. Accordingly, in addition to its heavy projections to the PVN, DMH sends moderate projections to the ventrolateral and dorsomedial PAG and ventromedial medulla (Hosoya, 1985; ter Horst and Luiten, 1986; Thompson et al., 1996; Hermann et al., 1997).

In contrast, the course of EW efferents is not as well defined, thus making it difficult to conclusively determine its connections to other virally infected brain regions. However, EW nucleus has been demonstrated recently to participate in responses to various stressors (Gaszner et al., 2004; Korosi et al., 2005). Thus, it is tempting to speculate that EW projects to the PVN, a major nucleus in orchestrating coordinated responses to stress (Sawchenko et al., 1996). The EW-PVN projection may participate in the coordination of stress responses across multiple brain regions.

Unlike EW, RN efferents are well characterized and project exclusively to the spinal cord (Ruigrok and Cella, 1995), thus making it the most likely synaptic site for this projection. Significant increases in the numbers of double-infected neurons in the $\mathrm{RN}$ at intermediate and late survival times may reflect the long distance of these second-order motor efferents.

In contrast to the $\mathrm{RN}$, the $\mathrm{PH}$ does not contain spinally projecting neurons but instead sends projections to the ventromedial medulla and the PAG (Vertes and Crane, 1996), which likely account for the later appearance of double-infected neurons within this area. A significant increase in labeling at the late survival suggests that there may be differences in transport times between these two projections, which are likely related to differences in terminal densities (Vertes and Crane, 1996).

It is likely that the double-labeled neurons observed in the motor cortex are higher-order neurons rather than those sending direct projections to the spinal cord. Appreciable numbers of such cells were detected at the late survival, thus supporting this notion. The most likely route of viral infection to the motor cortex is via the RN, which receives cortical afferents (Brown, 1974). These observations suggest a novel role for the motor cortex in sympatho-motor integration.

\section{Functional implications}

We found a significantly greater percentage of double-labeled neurons within the PVN, specifically PVNmpv, compared with most of the other subregions examined. Furthermore, the density of double-labeled neurons appeared to be higher with PVNmpv and PVNdp compared with other areas of similar size. These findings suggest that the PVN plays a major role in sympathomotor regulation. Traditionally, the PVN has been viewed as an integrative site for autonomic and endocrine responses to stress (Sawchenko et al., 1996). Our data are consistent with this notion and extend it to indicate the existence of cells within the PVN that have the potential to simultaneously regulate functions of the somatomotor efferents and the sympathetic nervous system. This sympatho-motor circuit is likely recruited during stressmotivated behaviors (e.g., fight-or-flight), which require concomitant activation of motor and sympathetic efferents.

Anxiety-induced behaviors and passive coping responses to chronic or inescapable stress may share certain behavioral and physiological characteristics such as a concomitant decrease in locomotor activity (freezing/immobility) and alterations in cardiovascular function. Neurons within the PVN appear to be recruited by such behavioral adaptations, because rats that have been bred for their helpless responses to chronic stress show ele- vated metabolism in the PVN (Shumake et al., 2001). Furthermore, this activation may be specific for the AVP-containing cells, because rats bred for high anxiety-related behavior show increased expression of AVP in response to an acute stressor (Murgatroyd et al., 2004). Similarly, rats that respond with prolonged inactivity to chronic stress show increased expression of AVP in the PVN (Murgatroyd et al., 2004).

OT also plays a role in mediating stress-motivated behaviors and, in particular, has been implicated in inhibiting aggressive behaviors (Harmon et al., 2002; Ragnauth et al., 2005). Together with the results of the present study, these data suggest that the AVP- and OT-positive sympatho-motor neurons identified in the present study mediate visceral and motor aspects of anxietylike and passive coping behaviors.

Interestingly, a previous postmortem study reported increased numbers of AVP- and OT-containing neurons in the PVN of depressed patients (Purba et al., 1996). This finding raises the possibility that sympatho-motor neurons may play some role in major depression and other mood disorders. Core symptoms of major depression include psychomotor retardation and hypoactivity (Nestler et al., 2002). Furthermore, depression and anxiety have been linked with a host of cardiovascular abnormalities (Roy et al., 1987; Rechlin et al., 1994; Carney et al., 1995; FrasureSmith et al., 1995; Watkins and Grossman, 1999; Agelink et al., 2001). Therefore, it seems likely that a portion of the doubleinfected neurons that we observed in the PVN, which contain AVP or OT, are involved in mediating passive coping responses to chronic stress and may also be involved in the expression of core symptoms of major depression.

Consistent with the proposed role in passive coping and quiescence for the circuits identified in our study is the finding of a large number of double-infected cells in the caudal ventrolateral PAG. Stimulation of this area produces quiescence and immobility with a reduction in locomotion in awake rats (Depaulis et al., 1994; Morgan et al., 1998; Morgan and Carrive, 2001) and also leads to hypotension (Carrive and Bandler, 1991; Lovick, 1992) and bradycardia (Morgan and Carrive, 2001).

In contrast to the passive coping areas discussed above, it seems likely that double-infected neurons identified in the DMH and dlLH play a role in active coping responses such as show of aggression and escape behaviors. The LH was one of the original areas implicated in the expression of the defense reaction: an integrated behavioral response that involves increased blood pressure, tachycardia, increased vocalization, and locomotion coupled with increased blood flow to the hindlimb (Hilton, 1982). This response can be elicited in experimental animals by exposure to a rival or a predator and can be mimicked by electrical stimulation of the LH (Hilton, 1982) or chemical disinhibition of this region (Kayaba et al., 2003). The descending component of the defense reaction is thought to be mediated in part by neurons in the dorsomedial PAG (Hilton and Redfern, 1986). However, we found relatively few double-labeled neurons in this region, suggesting that this response may be mediated by a small number of cells.

Similar to the LH, disinhibition of DMH elicits a defense reaction (Kunos and Varga, 1995). Furthermore, chemical stimulation of DMH produces somato-motor and autonomic changes that are characteristic of the defense reaction (DiMicco et al., 2002).

Based on our present findings, we hypothesize that the dual function neurons in the PVN and caudal vlPAG mediate passive coping responses. These circuits may also produce motor and autonomic disturbances characteristic of major depression. In 
contrast, sympatho-motor neurons in the DMH and LH may mediate active coping responses.

\section{References}

Abrahams VC, Hilton SM, Zbrozyna A (1960) Active muscle vasodilation produced by stimulation of the brain stem: its significance in the defence reaction. J Physiol (Lond) 154:491-513.

Abrahamson EE, Moore RY (2001) The posterior hypothalamic area: chemoarchitecture and afferent connections. Brain Res 889:1-22.

Agelink MW, Majewski T, Wurthmann C, Postert T, Linka T, Rotterdam S, Klieser E (2001) Autonomic neurocardiac function in patients with major depression and effects of antidepressive treatment with nefazodone. J Affect Disord 62:187-198.

Allen GV, Cechetto DF (1992) Functional and anatomical organization of cardiovascular pressor and depressor sites in the lateral hypothalamic area: I. Descending projections. J Comp Neurol 315:313-332.

Bandler R (1982) Induction of 'rage' following microinjections of glutamate into midbrain but not hypothalamus of cats. Neurosci Lett 30:183-188.

Bandler R, Carrive P, Zhang SP (1991) Integration of somatic and autonomic reactions within the midbrain periaqueductal grey: viscerotopic, somatotopic and functional organization. Prog Brain Res 87:269-305.

Beitz AJ (1995) Periaqueductal gray. In: The rat nervous system, Ed 2 (Paxinos G, ed), pp 173-182. San Diego: Academic.

Billig I, Foris JM, Card JP, Yates BJ (1999) Transneuronal tracing of neural pathways controlling an abdominal muscle, rectus abdominis, in the ferret. Brain Res 820:31-44.

Billig I, Foris JM, Enquist LW, Card JP, Yates BJ (2000) Definition of neuronal circuitry controlling the activity of phrenic and abdominal motoneurons in the ferret using recombinant strains of pseudorabies virus. J Neurosci 20:7446-7454.

Billig I, Hartge K, Card JP, Yates BJ (2001) Transneuronal tracing of neural pathways controlling abdominal musculature in the ferret. Brain Res 912:24-32.

Brown LT (1974) Corticorubral projections in the rat. J Comp Neurol 154:149-167.

Cannon WB (1963) The wisdom of the body. New York: W. W. Norton.

Cano G, Card JP, Sved AF (2004) Dual viral transneuronal tracing of central autonomic circuits involved in the innervation of the two kidneys in rat. J Comp Neurol 471:462-481.

Card JP (2001) Pseudorabies virus neuroinvasiveness: a window into the functional organization of the brain. Adv Virus Res 56:39-71.

Card JP, Rinaman L, Lynn RB, Lee BH, Meade RP, Miselis RR, Enquist LW (1993) Pseudorabies virus infection of the rat central nervous system: ultrastructural characterization of viral replication, transport, and pathogenesis. J Neurosci 13:2515-2539.

Carney RM, Saunders RD, Freedland KE, Stein P, Rich MW, Jaffe AS (1995) Association of depression with reduced heart rate variability in coronary artery disease. Am J Cardiol 76:562-564.

Carrive P, Bandler R (1991) Viscerotopic organization of neurons subserving hypotensive reactions within the midbrain periaqueductal grey: a correlative functional and anatomical study. Brain Res 541:206-215.

Daniels D, Miselis RR, Flanagan-Cato LM (1999) Central neuronal circuit innervating the lordosis-producing muscles defined by transneuronal transport of pseudorabies virus. J Neurosci 19:2823-2833.

Demmin GL, Clase AC, Randall JA, Enquist LW, Banfield BW (2001) Insertions in the gG gene of pseudorabies virus reduce expression of the upstream Us3 protein and inhibit cell-to-cell spread of virus infection. J Virol 75:10856-10869.

Depaulis A, Keay KA, Bandler R (1994) Quiescence and hyporeactivity evoked by activation of cell bodies in the ventrolateral midbrain periaqueductal gray of the rat. Exp Brain Res 99:75-83.

DiMicco JA, Samuels BC, Zaretskaia MV, Zaretsky DV (2002) The dorsomedial hypothalamus and the response to stress: part renaissance, part revolution. Pharmacol Biochem Behav 71:469-480.

Eldridge FL, Millhorn DE, Kiley JP, Waldrop TG (1985) Stimulation by central command of locomotion, respiration and circulation during exercise. Resp Physiol 59:313-337.

Enquist LW, Husak PJ, Banfield BW, Smith GA (1998) Infection and spread of alphaherpesviruses in the nervous system. Adv Virus Res 51:237-347.

Frasure-Smith N, Lesperance F, Talajic M (1995) Depression and 18-month prognosis after myocardial infarction. Circulation 91:999-1005.

Gaszner B, Csernus V, Kozicz T (2004) Urocortinergic neurons respond in a differentiated manner to various acute stressors in the Edinger-Westphal nucleus in the rat. J Comp Neurol 480:170-179.

Haring JH, Davis JN (1983) Acetylcholinesterase neurons in the lateral hypothalamus project to the spinal cord. Brain Res 268:275-283.

Harmon AC, Huhman KL, Moore TO, Albers HE (2002) Oxytocin inhibits aggression in female Syrian hamsters. J Neuroendocrinol 14:963-969.

Hermann DM, Luppi PH, Peyron C, Hinckel P, Jouvet M (1997) Afferent projections to the rat nuclei raphe magnus, raphe pallidus and reticularis gigantocellularis pars alpha demonstrated by iontophoretic application of choleratoxin (subunit b). J Chem Neuroanat 13:1-21.

Hilton SM (1982) The defence-arousal system and its relevance for circulatory and respiratory control. J Exp Biol 100:159-174.

Hilton SM, Redfern WS (1986) A search for brain stem cell groups integrating the defence reaction in the rat. J Physiol (Lond) 378:213-228.

Hosoya Y (1980) The distribution of spinal projection neurons in the hypothalamus of the rat, studied with the HRP method. Exp Brain Res 40:79-87.

Hosoya Y (1985) Hypothalamic projections to the ventral medulla oblongata in the rat, with special reference to the nucleus raphe pallidus: a study using autoradiographic and HRP techniques. Brain Res 344:338-350.

Jänig W, McLachlan EM (1992) Characteristics of function-specific pathways in the sympathetic nervous system. Trends Neurosci 15:475-481.

Jordan D (1990) Autonomic changes in affective behavior. In: Central regulation of autonomic functions (Loewy AD, Spyer KM, eds), pp 349-366. New York: Oxford UP.

Kayaba Y, Nakamura A, Kasuya Y, Ohuchi T, Yanagisawa M, Komuro I, Fukuda Y, Kuwaki T (2003) Attenuated defense response and low basal blood pressure in orexin knockout mice. Am J Physiol Regul Integr Comp Physiol 285:R581-R593.

Kerman IA, McAllen RM, Yates BJ (2000a) Patterning of sympathetic nerve activity in response to vestibular stimulation. Brain Res Bull 53:11-16.

Kerman IA, Emanuel BA, Yates BJ (2000b) Vestibular stimulation leads to distinct hemodynamic patterning. Am J Physiol Regul Integr Comp Physiol 279:R118-R125.

Kerman IA, Enquist LW, Watson SJ, Yates BJ (2003) Brainstem substrates of sympatho-motor circuitry identified using trans-synaptic tracing with pseudorabies virus recombinants. J Neurosci 23:4657-4666.

Kim JS, Enquist LW, Card JP (1999) Circuit-specific coinfection of neurons in the rat central nervous system with two pseudorabies virus recombinants. J Virol 73:9521-9531.

Kohler C, Haglund L, Swanson LW (1984) A diffuse alpha MSHimmunoreactive projection to the hippocampus and spinal cord from individual neurons in the lateral hypothalamic area and zona incerta. J Comp Neurol 223:501-514.

Korosi A, Schotanus S, Olivier B, Roubos EW, Kozicz T (2005) Chronic ether stress-induced response of urocortin 1 neurons in the EdingerWestphal nucleus in the mouse. Brain Res 1046:172-179.

Kunos G, Varga K (1995) The tachycardia associated with the defense reaction involves activation of both $\mathrm{GABA}_{\mathrm{A}}$ and $\mathrm{GABA}_{\mathrm{B}}$ receptors in the nucleus tractus solitarii. Clin Exp Hypertens 17:91-100.

Lovick TA (1991) Central nervous system integration of pain control and autonomic function. News Physiol Sci 6:82-86.

Lovick TA (1992) Inhibitory modulation of the cardiovascular defence response by the ventrolateral periaqueductal grey matter in rats. Exp Brain Res 89:133-139.

Mancia G, Zanchetti A (1981) Hypothalamic control of autonomic functions. In: Behavioral studies of the hypothalamus (Morgane PJ, Panksepp J, eds), pp 147-202. New York: Marcel Dekker.

Marson L, Foley KA (2004) Identification of neural pathways involved in genital reflexes in the female: a combined anterograde and retrograde tracing study. Neuroscience 127:723-736.

McLean IW, Nakane PK (1974) Periodate-lysine-paraformaldehyde fixative. A new fixation for immunoelectron microscopy. J Histochem Cytochem 22:1077-1083.

Morgan MM, Carrive P (2001) Activation of the ventrolateral periaqueductal gray reduces locomotion but not mean arterial pressure in awake, freely moving rats. Neuroscience 102:905-910.

Morgan MM, Whitney PK, Gold MS (1998) Immobility and flight associated with antinociception produced by activation of the ventral and lat$\mathrm{eral} /$ dorsal regions of the rat periaqueductal gray. Brain Res 804:159-166. Mouton LJ, Holstege G (1994) The periaqueductal gray in the cat projects to 
lamina VIII and the medial part of lamina VII throughout the length of the spinal cord. Exp Brain Res 101:253-264.

Murgatroyd C, Wigger A, Frank E, Singewald N, Bunck M, Holsboer F, Landgraf R, Spengler D (2004) Impaired repression at a vasopressin promoter polymorphism underlies overexpression of vasopressin in a rat model of trait anxiety. J Neurosci 24:7762-7770.

Nestler EJ, Barrot M, DiLeone RJ, Eisch AJ, Gold SJ, Monteggia LM (2002) Neurobiology of depression. Neuron 34:13-25.

Palmer AA, Printz MP (1999) Strain differences in Fos expression following airpuff startle in Spontaneously Hypertensive and Wistar Kyoto rats. Neuroscience 89:965-978.

Paxinos G, Watson C (1986) The rat brain in stereotaxic coordinates, Ed 2. San Diego: Academic.

Purba JS, Hoogendijk WJ, Hofman MA, Swaab DF (1996) Increased number of vasopressin- and oxytocin-expressing neurons in the paraventricular nucleus of the hypothalamus in depression. Arch Gen Psychiatry 53:137-143.

Ragnauth AK, Devidze N, Moy V, Finley K, Goodwillie A, Kow LM, Muglia LJ, Pfaff DW (2005) Female oxytocin gene-knockout mice, in a seminatural environment, display exaggerated aggressive behavior. Genes Brain Behav 4:229-239.

Rechlin T, Weis M, Spitzer A, Kaschka WP (1994) Are affective disorders associated with alterations of heart rate variability? J Affect Disord 32:271-275.

Roy A, Guthrie S, Pickar D, Linnoila M (1987) Plasma norepinephrine responses to cold challenge in depressed patients and normal controls. Psychiatry Res 21:161-168.

Ruigrok TJH, Cella F (1995) Precerebellar nuclei and red nucleus. In: The rat nervous system (Paxinos G, ed), pp 277-308. San Diego: Academic.

Saper CB, Loewy AD, Swanson LW, Cowan WM (1976) Direct hypothalamo-autonomic connections. Brain Res 117:305-312.

Saper CB, Swanson LW, Cowan WM (1979) An autoradiographic study of the efferent connections of the lateral hypothalamic area in the rat. J Comp Neurol 183:689-706.

Sawchenko PE, Brown ER, Chan RK, Ericsson A, Li HY, Roland BL, Kovacs KJ (1996) The paraventricular nucleus of the hypothalamus and the functional neuroanatomy of visceromotor responses to stress. Prog Brain Res 107:201-222.

Shiosaka S, Kawai Y, Shibasaki T, Tohyama M (1985) The descending alpha-MSHergic (alpha-melanocyte-stimulating hormone-ergic) projections from the zona incerta and lateral hypothalamic area to the inferior colliculus and spinal cord in the rat. Brain Res 338:371-375.

Shumake J, Edwards E, Gonzalez-Lima F (2001) Hypermetabolism of paraventricular hypothalamus in the congenitally helpless rat. Neurosci Lett 311:45-48.
Smith BN, Banfield BW, Smeraski CA, Wilcox CL, Dudek FE, Enquist LW, Pickard GE (2000) Pseudorabies virus expressing enhanced green fluorescent protein: a tool for in vitro electrophysiological analysis of transsynaptically labeled neurons in identified central nervous system circuits. Proc Natl Acad Sci USA 97:9264-9269.

Standish A, Enquist LW, Miselis RR, Schwaber JS (1995) Dendritic morphology of cardiac related medullary neurons defined by circuit-specific infection by a recombinant pseudorabies virus expressing betagalactosidase. J Neurovirol 1:359-368.

Swanson LW (1987) The hypothalamus. In: Integrated systems of the CNS, Part I (Björklund A, Hökfelt T, Swanson LW, eds), pp 1-124. Amsterdam: Elsevier.

Swanson LW (2004) Brain maps: structure of the rat brain, Ed 3. Amsterdam: Elsevier.

Swanson LW, Kuypers HG (1980) The paraventricular nucleus of the hypothalamus: cytoarchitectonic subdivisions and organization of projections to the pituitary, dorsal vagal complex, and spinal cord as demonstrated by retrograde fluorescence double-labeling methods. J Comp Neurol 194:555-570.

ter Horst GJ, Luiten PG (1986) The projections of the dorsomedial hypothalamic nucleus in the rat. Brain Res Bull 16:231-248.

Thompson RH, Canteras NS, Swanson LW (1996) Organization of projections from the dorsomedial nucleus of the hypothalamus: a PHA-L study in the rat. J Comp Neurol 376:143-173.

Vahlne A, Nystrom B, Sandberg M, Hamberger A, Lycke E (1978) Attachment of herpes simplex virus to neurons and glial cells. J Gen Virol 40:359-371.

Vahlne A, Svennerholm B, Sandberg M, Hamberger A, Lycke E (1980) Differences in attachment between herpes simplex type 1 and type 2 viruses to neurons and glial cells. Infect Immun 28:675-680.

Vertes RP, Crane AM (1996) Descending projections of the posterior nucleus of the hypothalamus: phaseolus vulgaris leucoagglutinin analysis in the rat. J Comp Neurol 374:607-631.

Waldrop TG, Eldridge FL, Iwamoto GA, Mitchell JH (1996) Central neural control of respiration and circulation during exercise. In: Handbook of physiology, Sec 12, Exercise: regulation and integration of multiple systems (Rowell LB, Shepherd JT, eds), pp 333-380. New York: Oxford UP.

Watkins LL, Grossman P (1999) Association of depressive symptoms with reduced baroreflex cardiac control in coronary artery disease. Am Heart J 137:453-457.

Yardley CP, Hilton SM (1986) The hypothalamic and brainstem areas from which the cardiovascular and behavioural components of the defence reaction are elicited in the rat. J Auton Nerv Syst 19:127-136. 